\title{
Phonotactic probabilities in young children's speech production*
}

\author{
TANIA S. ZAMUNER \\ University of Nijmegen \\ LOUANN GERKEN AND MICHAEL HAMMOND \\ University of Arizona
}

(Received I6 August 2002. Revised 28 August 2003)

\section{A BSTRACT}

This research explores the role of phonotactic probability in two-yearolds' production of coda consonants. Twenty-nine children were asked to repeat $\mathrm{CVC}$ non-words that were used as labels for pictures of imaginary animals. The CVC non-words were controlled for their phonotactic probabilities, neighbourhood densities, word-likelihood ratings, and contained the identical coda across low and high phonotactic probability pairs. This allowed for comparisons of children's productions of the same coda consonant in low and high phonotactic probability environments. Children were significantly more likely to produce the same coda in high phonotactic probability non-words than in low phonotactic probability non-words. These results are consistent with the hypothesis that phonotactic probability is a predictor of coda production in English. Moreover, this finding provides further evidence for the role of the input and distribution of sound patterns in the ambient language as a basis for phonological acquisition.

\section{INTRODUCTION}

The errors children make when producing their early words have been taken to reflect children's phonological knowledge and representations. For example, children's early words are largely characterized by an open syllable shape. A child producing the final /n/ in 'man', might delete /n/ and produce $[\mathrm{mæ}],[\mathrm{m} \varepsilon]$ or $[\mathrm{m} \Lambda]$ (Demuth \& Fee, I 995). One interpretation of this

[*] This research was supported by NSERC PGSB awarded to T. S. Zamuner and by NSF grant \#SBR 969607 awarded to LouAnn Gerken. Thanks to assistance and comments from Paula Fikkert, Paul Luce, Diane Ohala, Maryam Sadrzadeh, Joe Pater, Joseph Stemberger, and two anonymous reviewers. Address for correspondence: Tania S. Zamuner, University of Nijmegen, IWTS, P.O. Box 310, 6500 AH Nijmegen, The Netherlands.e-mail: T.Zamuner@mpl.nl 
phenomenon is that final consonant deletion is the result of innate pressures children have to adapt their words to the universally preferred CV shape. Thus, these types of errors have been traditionally interpreted as a reflection of innate universal grammar (e.g. Jakobson, r 94I/r 968 ; and others).

In contrast with the view that children's utterances reflect a universally available default state, there is considerable evidence that child language reflects language-specific input at an early age. The specific property of the input that we will examine here is phonotactic probabilities, which concerns the likelihood of sounds' occurrences. For example, in English there are phonotactic constraints where / $\mathrm{y} /$ can only occur in syllable-final position, as in 'wing' /win/, and /h/ cannot occur in the same syllable-final position. There are also less absolute or gradient constraints. For example, /3/ occurs word-finally in a total of three CVC words in the Webster's Lexicon (Webster, r964): 'beige', 'rouge' and 'loge'; thus, /3/ has a very low probability of occurrence in this position. Other codas, however, occur at the end of many CVC words, such as /t/ as in 'fight', 'hat', 'hit', 'net', 'lout', 'shoot'; thus, the probability of $/ \mathrm{t} /$ occurring in word-final position is high.

Phonotactic probabilities are used to measure these gradient distributions, and they can be calculated according to segmental positional probabilities and biphoneme probabilities. Segment positional probabilities refer to the likelihood of phonemes occurring in the onset, vowel and coda position $(\mathrm{C}-\mathrm{V}-\mathrm{C})$, as in the examples above. Biphoneme probabilities refer to the likelihood that phonemes are preceded or followed by other phonemes, that is, the likelihood of an onset-vowel sequence and a vowel-coda sequence ( $\mathrm{CV}$ and $\mathrm{VC}$, respectively). Phonotactic probabilities can be calculated across single and multi-syllable words and across words with various stress patterns (e.g. Messer, I967; Pierrehumbert, I 994; Hammond, 200 I ; see Munson, 200I for a recent review of this literature). Although considerable work has been done on words with different syllable lengths and stress patterns, the focus of this research is on phonotactic probabilities in CVC non-words.

A variety of tasks have been employed to test speakers' sensitivities to the distribution of sounds in CVC non-words. Consistently, research has found that infants, young children and adults are sensitive to non-words' phonotactic probabilities. Across age groups, a preference is found for CVC non-words exhibiting high phonotactic probabilities over those exhibiting low phonotactic probabilities. For example, Jusczyk, Luce \& Charles-Luce (r 994) presented infants with lists of CVC non-words with either low or high phonotactic probabilities and found that by 0 ; 9 , infants preferred to listen to lists of high phonotactic probability non-words. The results of Jusczyk et al. were extended to infants at $0 ; 7$, who were also found to prefer list of high phonotactic probability non-words, using the stimuli described in 
this paper (Zamuner, 2003). This demonstrates that even at an early age and before the onset of meaningful speech, infants are sensitive to the frequency of the sound patterns in the ambient language, and that they are able to encode this information at some level. Other studies, such as that by Treiman, Kessler, Knewasser, Tincoff \& Bowman (2000) revealed that subjects maintained the integrity of frequent $\mathrm{VC}$ rhymes more than infrequent $\mathrm{VC}$ rhymes in a non-word blending task. Similar sensitivities are illustrated in Storkel (200I), who found that children learn high phonotactic probability non-words with fewer exposures than non-words with low probabilistic phonotactics. Lastly, studies using non-word repetition tasks (Vitevitch \& Luce, I998) and same-different word decision tasks (Vitevitch \& Luce, I 999) have shown that reaction times are faster for items with high phonotactic probabilities over those with low phonotactic probabilities.

The current study had two goals. The first goal was to determine whether children's coda productions would be influenced by the non-word's phonotactic probabilities. Although a few studies have looked at the relationship between coda consonant acquisition and the frequency of codas in the input language (Bernstein-Ratner, I 994; Stoel-Gammon, I 998; Zamuner, 2003), research has not yet determined whether a particular coda is differentially produced depending on a non-word's phonotactic probabilities. Thus, the main goal of the study was to compare children's productions of the same coda consonant in low and high phonotactic probability environments. The prediction was that children's productions of the same coda consonant would differ according to the environment in which the coda occurred. In this case, /d/ will be produced more often in high phonotactic probability non-words than in low phonotactic probability non-words. For example, we predicted that children would be more likely to preserve the coda $/ \mathrm{d} / \mathrm{in}$ $/ \mathrm{g} \varepsilon \mathrm{d} /$ and more likely to delete or modify the coda $/ \mathrm{d} / \mathrm{in} / \mathrm{t} \int \Lambda \mathrm{d} /$. The rationale was that, if phonotactic probability differentially affects children's production of a coda such as /d/, we would have evidence that the frequency of sounds in the ambient language plays a substantial role in children's acquisition and production of phonological structures, and we would have evidence that young children have detailed phonological representations. Such a finding would also suggest that children's productive language reflects their experience with language, to an even greater extent than previously reported in phonological acquisition.

The second goal was to compare the data from the current study to previous research. Beckman \& Edwards (2000) examined children's productions of onsets, rhymes and clusters in disyllabic and trisyllabic nonwords. Non-words were controlled for familiar sequences (occurring often in a corpus of first grader's spontaneous speech) or novel sequences (legal sequences in English that did not occur in this corpus). Results of their study showed effects of Familiar vs. Novel in children's production of CVs 
and CCs, but not a significant effect with children's production of rhymes, VCs. To determine whether children's rhyme productions are significantly effected by phonotactic probabilities in monosyllabic non-words, children's rhyme productions in this study were also analysed. Other researchers who have asked questions similar to those address here have focused on the productions of older children (Treiman et al., 2000, $M=8$; г ; Beckman \& Edwards, 2000, $M=4$; ; Edwards, Beckman \& Munson, 200 I, range= 3;2-8; го; Munson, 200 I, $M=3$; го). However, by the age of 3 ; o, children are already phonologically advanced; therefore, an attempt was made to study children at the first stages of word production, as young as $\mathrm{I} ; 8$. Lastly, Edwards et al. (200 I) revealed that effects of phonotactic probability in children's production accuracy are also related to children's vocabulary size. Thus, children's performance in this study was also correlated with vocabulary size.

\section{METHOD}

\section{Participants}

Participants in the main study were 29 children between the ages of $\mathrm{I} ; 8-2 ; 4$ $(M=2 ; 0)$, I 6 males and I 3 females, with a mean MLU of $\mathrm{I} \cdot 73$. All children were monolingual speakers of English with no history of speech or hearing impairment as determined by parent questionnaire. Included in the analyses were 3 subjects who had exposure to Spanish for no more than io hours a week. Parents also completed the MacArthur Communicative Development Inventory (CDI) (Fenson, Dale, Reznick, Thal, Bates, Hartung, Pethick \& Reilly, I993) and subjects had to achieve above the roth percentile on the Part A: Vocabulary Checklist for inclusion in the experiment (range Io-95th percentile, $M=52 \cdot 4$ ). Subjects were recruited through the Language Acquisition Lab at the University of Arizona. The experiment employed a within-subjects design and all subjects were tested on the same stimuli.

\section{Stimuli}

The process of selecting the stimuli for the study involved several steps, including pre-testing with adult participants. Therefore, the stimuli selection process will be described before turning to the procedure and analyses.

The stimuli consisted of 22 CVC non-words that were controlled for phonotactic probabilities (low and high), vowel quality (lax, tense and diphthong), and coda type /d, l, s, g, v, $\mathrm{y}, \mathrm{m} /$. The decision to control for vowel quality was based upon previous research showing that children differentially produce codas depending on the preceding vowels (Fikkert, I 994). The selection of coda types was based on the set of possible codas 
given the restrictions of probabilistic phonotactics and vowel quality. Each of the 22 non-words was associated with a picture of an imaginary animal. In total there were I I pairs of non-words, each with the same vowel quality and identical coda. The complete list of non-word pairs is given in Table $\mathbf{I}$.

Calculating phonotactic probabilities. The phonotactic probabilities of the non-word stimuli were based on the CVC words from a corpus of child directed speech (CDSC). Calculations were based solely on CVC words to restrict the influence of stress on coda calculations, because segmental distributions vary in different prosodic positions (e.g. Zamuner, 2003). In addition, CCVC words were excluded because there are some dependencies between certain onset clusters in English and the following coda. Davis ( I989) describes a constraint in English against sCVC sequences where consonants have both labial or dorsal place of articulation. This restriction does not hold in CVC words, therefore, probabilities were based on just the set of CVC words. To create this corpus, parental speech (this included both adult-directed and child-directed speech) was taken from CHILDES studies involving children between the ages of I ; 7-2;4 (see Zamuner, 2003 for references). Phonetic transcriptions were obtained from the electronic version of the Webster's Dictionary of American English (Webster, I 964). In some instances the dictionary did not contain the phonetic transcriptions, e.g. for the plural word 'boys'. All these remaining cases were transcribed by hand, based on other words in the dictionary and the authors' intuitions. All proper names were then excluded (27 types, 633 tokens). It was assumed that this type of input varies greatly across children due to children having different personal names and different names from popular culture. The resulting CDSC consisted of 489 I unique types, with I 43496 word tokens. The CVC word corpus extracted from the CDSC consisted of 604 word types and 40822 word tokens.

CVC words were marked for whether they were content or function words (e.g. 'sock' vs. 'that'), and for whether they were monomorphemic or bimorphemic (e.g. 'sock' vs. 'boys'). This allowed phonotactic probability calculations to be controlled for word class and morphology for the following reasons. One argument against a frequency-based account of phonological acquisition is the fact that /ð/ is frequent in English, yet acquired late (e.g. Moskowitz, I970, p. 429). However, /ð/ is frequent largely because it appears in English function words (i.e. 'there' appears I 25 times and 'this' appears I 690 times in the CDSC), and children initially delete function words (Brown, I973). Controlling for word class might account for some of the disparities between frequency and acquisition (also see Bernstein-Ratner, I994 for a discussion). This is especially true if the targets young children attempt to produce have a strong effect in children's phonological development. Research has shown that children differentially produce phonemes depending on their morphological status (Brown, I973). 
To this extent, words in the corpus were marked for word class and morphological complexity as a first attempt to control for these factors.

Segmental positional probabilities and biphoneme probabilities were calculated on the log frequency weighted counts (token word counts) of CVC words from the CDSC. Once the phonotactic probabilities of all CVC words were calculated, average phonotactic probabilities were calculated on various subsets of the lexical set using: (a) all words in the corpus; (b) excluding function words; (c) excluding bimorphemic words; and (d) excluding function words and bimorphemic words. The final lists of $\mathrm{C}-\mathrm{V}-\mathrm{C}$ and $\mathrm{CV}-\mathrm{VC}$ probabilities were taken from the averages across the lists (a) to $(\mathrm{d})$. $^{1}$

All non-words contained legal phoneme sequences for English. Although /tes/ 'Tess', /dzכis/ 'Joyce', /lom/ 'loin' and /rain/ 'Rhine' are real words, it was assumed that their frequencies were low enough to function as non-words for the purposes of the experiment. The presence of these real words was unavoidable, given the restrictions on vowel quality, the requirement that pairs of words needed to contain the same coda consonant, and because we wanted to test a range of coda consonants. In some dialects of English, $\left[\mathrm{p}_{\Lambda} \mathrm{l}\right]$ is an accepted pronunciation of 'pull' and [gel] is acceptable for 'girl'.

Neighbourhood density of stimuli. Neighbourhood densities of the nonword stimuli were calculated based on two sources: the CDSC, and the Webster's dictionary (Webster, I964). Results were the same from both sources. Low phonotactic probability non-words had fewer neighbours than their paired high phonotactic probability non-words. This was significant based on the CDSC, $t(\mathrm{ro})=-8 \cdot 22, p<0.00 \mathrm{I}$, one-tailed. This was also significant based on the Webster's dictionary, $t(\mathrm{I} \circ)=-3 \cdot 2 \mathrm{I}, p<0 \cdot 0 \mathrm{I}$, onetailed.

Adult word-likelihood rating of stimuli. To determine whether the stimuli created here had the same phonological properties as in previous studies, adult subjects were asked to judge the relative wellformedness of the CVC non-words. Treiman et al. (2000) found that in non-word decision tasks, young children and adults judge high phonotactic probability non-words as more 'word-like' than low phonotactic probability non-words. Thus, the prediction was that subjects would rate the non-words from this study in the same way. Fifteen adult monolingual speakers of English were asked to rate the non-words on a scale of $\mathrm{I}_{-5}$, depending on the non-words' relative word-likelihood or how much they sounded like possible English words

[I] To check whether these calculations made any significant change on the status of the phonotactic probabilities of the non-words used in this experiment, phonotactic probabilities were recalculated using all words in the CVC corpus based on type and token counts. Based on this recalculation, all low phonotactic probability non-words had lower probabilities than their matched high phonotactic probability non-word pairs. 
( $\mathrm{I}=$ relatively poor English word and $5=$ relatively good English word). An analysis by subjects revealed that participants were more likely to judge high phonotactic probability non-words as more word-like $(M=37 \cdot 27$, $S . D .=8 \cdot 22)$ than their paired low phonotactic probability non-words $(M=34 \cdot 4, \quad S . D .=5 \cdot 36)$. This difference was significant $\left(t\left(\mathrm{I}_{4}\right)=-\mathrm{I} \cdot 92\right.$, $p<0.05$, one-tailed). An items analysis also revealed that high phonotactic probability non-words were considered to be more word-like $(M=32 \cdot 64$, $S . D .=4 \cdot \mathrm{I} 3)$ than their low phonotactic probability non-words pairs $(M=29 \cdot 64, S . D .=8 \cdot \mathrm{I})$. This difference, however, was not significant, $t(\mathrm{I} 0)=-\mathrm{I} \cdot \mathrm{I} 8, p=0 \cdot \mathrm{I} 3$, one-tailed. The lack of a significant effect by items is probably due to the fact that some of the low probability non-word stimuli are low frequency English words (e.g. 'Joyce').

Adult productions of coda in non-words stimuli. A pilot study was also conducted with five monolingual English-speaking adult subjects to ensure that they could correctly perceive and produce codas in both the low and high phonotactic probability non-words, and were therefore suitable to test with children. Adults were presented with the pre-recorded stimuli and asked to repeat the names of the animals. Only one coda error on these stimuli was made, in which /nin/ was produced as [nid] 'need'.

\section{Procedure}

The experiment consisted of a non-word repetition task. Children were presented with pre-recorded non-words and their corresponding pictures of nonsense animals on a computer using PowerPoint. The pre-recorded non-words were played over a set of speakers. Non-words were presented in a randomly ordered list. All children received the same randomised order, along with 20 fillers consisting of VC non-words. These VC non-words were made to test children's production of English coda consonants in the absence of a preceding onset, which might induce place of articulation changes in the following coda. However, the phonological composition of these non-words were like English function words (short vowel + coda) and it was decided that they were not enough like English content words to warrant analysis. Participants were tested in the Language Acquisition Lab at the University of Arizona with the exception of 5 participants who were tested in their homes, and sessions were videotaped and DAT recorded, respectively. All sessions were transcribed on-line and checked afterwards by a research assistant naïve to the goal of the experiment. Agreement between the two transcribers was calculated as $98.94 \%$ (based on $17 \%$ of the data).

Children were told that they would be shown pictures of funny animals and that their job was to repeat the names of the animals. They were given two practice items of a bear and a pig. Once the child mastered the task, the 
experiment began. Children were allowed to hear repeated presentations of the stimuli. However, if a child appeared disinterested in a particular stimulus after one or two repetitions, the experimenter went on to the next item.

\section{RESULTS}

\section{Data coding}

Responses were coded into five bins, based on broad transcriptions of children's productions: coda produced correctly (Correct), coda produced incorrectly (Incorrect), no coda produced (No Coda), no response (No Response), and real word response (Real Word). Examples of coding are illustrated with the pair $/ \mathrm{t} \int \Lambda \mathrm{d} /$ and $/ \mathrm{g} \varepsilon \mathrm{d} /$. The responses $\left[\mathrm{t} \int \Lambda \mathrm{d}\right]$ or $[\mathrm{t} \Lambda \mathrm{d}]$, and [ged] were coded as correct; $\left[\mathrm{t} \int \Lambda \mathrm{t}\right],[\mathrm{t} \Lambda \mathrm{ts}],[\mathrm{g} \varepsilon \mathrm{d} \partial]$ and $\left[\mathrm{g}_{\varepsilon} \mathrm{d}_{3}\right]$ as incorrect, ${ }^{2}$ $\left[\mathrm{t} \int \Lambda\right]$ and $[\mathrm{ga}]$ were coded as No Coda responses, and [t $\left.\Lambda \mathrm{t} \int\right]$ 'touch' and [ded] 'dead' were coded as Real Word responses. The criterion for Real Word response was based on whether the children's production occurred in the CDSC. Based on this criterion, real word responses such as 'choice' and 'test' were excluded, but infrequent real word responses such as 'chug' for $/ \mathrm{t} \int \Lambda \mathrm{d} /$ were not excluded. In the latter case it was assumed that these real word productions were the result of speech production errors and not a real word substitution. Only children's first response was recorded. Results by items are given in Table $\mathbf{I}$. Although all children completed the entire experiment, a subset of the children lost interest towards the end; therefore, certain items have more non-responses than others.

Because there were an unequal number of No Responses in the low vs. high phonotactic probability non-words, a weighted statistic of children's correct coda responses was calculated, both by subjects and by items. This was computed by taking the number of non-words produced with the coda, divided by the number of times the non-word with the coda could have been produced. This proportion was then multiplied by the number of correctly produced codas. For example, in an items analysis, the non-word $/ \mathrm{t} \int \Lambda \mathrm{d} /$ was produced 27 times (two of the 29 subjects did not produce a response). This proportion was then multiplied by the number of times the

[2] There were fourteen cases in which there was vowel epenthesis. In eight of these cases, the identity of the target coda was different. In six of these cases the target codas was identical to the output form: two in low phonotactic probability non-words, and four in high phonotactic probability non-words. These correct 'target codas' were considered incorrect productions because of their presumed syllabification in the disyllable form (the intervocalic consonant forms the onset of the second syllable. This has been argued to be a strategy children use to avoid producing codas - a vowel in inserted after final consonants, e.g. CVC. $\rightarrow$ CV.CV (Demuth \& Fee, I 995). 
TABLE I. Response type for low and high phonotactic probability non-words, by items

\begin{tabular}{|c|c|c|c|c|c|c|c|c|c|c|c|}
\hline \multirow{2}{*}{\multicolumn{2}{|c|}{$\begin{array}{l}\text { Phonotactic } \\
\text { probability }\end{array}$}} & \multicolumn{10}{|c|}{ Response type } \\
\hline & & \multicolumn{2}{|c|}{ Correct } & \multicolumn{2}{|c|}{ Incorrect } & \multicolumn{2}{|c|}{ No coda } & \multicolumn{2}{|c|}{ No response } & \multicolumn{2}{|c|}{ Real word } \\
\hline Low & High & Low & High & Low & High & Low & High & Low & High & Low & High \\
\hline $\mathrm{t} \int_{\Lambda} \mathrm{d}$ & $\mathrm{g} \varepsilon \mathrm{d}$ & 7 & II & I 6 & 8 & I & I & 2 & $\circ$ & 3 & 9 \\
\hline $\mathrm{p}_{\Lambda} \mathrm{l}$ & $\mathrm{g} \varepsilon \mathrm{l}$ & 3 & I3 & 9 & 2 & I 3 & 4 & $\circ$ & I & 4 & 9 \\
\hline $\mathrm{d}_{3} \Lambda \mathrm{S}$ & tes & I3 & 16 & 4 & 4 & 0 & 0 & IO & 8 & 2 & I \\
\hline$\theta æ g$ & sig & 7 & I 4 & 20 & 9 & I & 2 & $\circ$ & $\circ$ & I & 4 \\
\hline zev & div & 5 & 5 & I 4 & I I & 2 & ० & 8 & IO & 0 & 3 \\
\hline $\int \Lambda \eta$ & bin & 6 & I I & IO & 9 & 3 & $\circ$ & 8 & 6 & 2 & 3 \\
\hline gim & bom & 8 & 3 & 7 & 6 & 2 & I & I & I & I I & I 8 \\
\hline von & $\operatorname{nin}$ & 6 & I 4 & 7 & I & 3 & I & $\circ$ & o & I3 & I 3 \\
\hline $\mathrm{d}_{3}$ गIs & fais & I 7 & 18 & 4 & 4 & 2 & I & I & 3 & 5 & 3 \\
\hline lon & rain & 5 & 8 & 3 & 2 & I & 4 & 9 & IO & I I & 5 \\
\hline mord & nard & 8 & 9 & 7 & 7 & I & 3 & I 2 & 9 & I & I \\
\hline Total & & 85 & 122 & IOI & 63 & 29 & I 7 & $5 \mathrm{I}$ & 48 & 53 & 69 \\
\hline
\end{tabular}

coda was correctly produced $((27 / 29) * 7)$. The weighted response is given by subjects in Table 2 , and by items in Table 3 .

\section{Analyses}

Two sets of analyses were performed on the data. In keeping with the main goal of the experiment, the first analyses tested the hypothesis that phonotactic probability influences children's coda production. Four follow-up analyses tested alternative accounts of the effect of phonotactic probability revealed by the first analyses. In keeping with the secondary goal of the study, a third and final set of analyses was performed to compare the current results with those from previous studies. Analyses in the third set focused on rhyme production and the relation of age and vocabulary size to coda production accuracy.

Beginning with the most direct test of the hypothesis that phonotactic probability affects young children's coda productions, the first analyses examined children's accurate coda productions. An analysis by subjects revealed that children were more likely to produce codas accurately in high phonotactic probability non-words $(M=3 \cdot 82$, S.D. $=2 \cdot 19)$ than in low phonotactic probability non-words $(M=2 \cdot 66, S . D .=\mathrm{I} \cdot 7 \mathrm{I})$. This difference was significant, $t(28)=-3.59, p<0.00 \mathrm{I}$, one-tailed paired $t$-test. Eight of the I I items were also produced more accurately in the high probability nonwords $(M=9 \cdot 6 \circ, S . D .=4 \cdot 6 \mathrm{I})$ than in the low probability version $(M=6 \cdot 48$, $S . D .=3.77)$. This difference was also significant, $t(\mathrm{I} 0)=-2.48, p<0.05$, 
TA B LE 2. Weighted response by subjects, for correct codas in low and high phonotactic probability non-words

\begin{tabular}{|c|c|c|}
\hline \multirow[b]{2}{*}{ Subject } & \multicolumn{2}{|c|}{ Correct } \\
\hline & Low & High \\
\hline I. & 0.82 & 3.00 \\
\hline 2. & $2 \cdot 00$ & 4.00 \\
\hline 3. & I.09 & I.09 \\
\hline 4. & 0.00 & $3 \cdot 64$ \\
\hline 5. & $3 \cdot 00$ & $4 \cdot 00$ \\
\hline 6. & 0.55 & 0.45 \\
\hline 7. & $4 \cdot 00$ & $6 \cdot 00$ \\
\hline 8. & $I \cdot 36$ & I.09 \\
\hline 9. & I $\cdot 00$ & $6 \cdot 00$ \\
\hline Io. & I $\cdot 82$ & 5.00 \\
\hline II & 3.00 & $3 \cdot 64$ \\
\hline I 2. & $5 \cdot 00$ & $7 \cdot 00$ \\
\hline I 3. & 0.00 & I 64 \\
\hline I 4. & $3 \cdot 00$ & $2 \cdot 00$ \\
\hline I 5. & $3 \cdot 64$ & $3 \cdot 82$ \\
\hline I 6. & $2 \cdot 00$ & 4.00 \\
\hline I 7. & $3 \cdot 00$ & 4.00 \\
\hline I 8. & $4 \cdot 00$ & $6 \cdot 00$ \\
\hline I 9. & $3 \cdot 64$ & $\mathrm{I} \cdot 82$ \\
\hline 20. & I.09 & $I \cdot 9 I$ \\
\hline $2 \mathrm{I}$ & 5.00 & $2 \cdot 00$ \\
\hline 22. & $4 \cdot 0 \circ$ & 8.00 \\
\hline 23. & $5 \cdot 00$ & $7 \cdot 00$ \\
\hline 24 & $5 \cdot 00$ & $4 \cdot 00$ \\
\hline 25. & $5 \cdot 00$ & $6 \cdot 00$ \\
\hline 26. & 3.00 & $5 \cdot 00$ \\
\hline 27 & 0.36 & 0.27 \\
\hline 28 & 5.00 & $7 \cdot 00$ \\
\hline 29. & $0.9 \mathrm{I}$ & I. 36 \\
\hline
\end{tabular}

one-tailed paired $t$-test. Another analysis was done which included children's correct codas from Real Word responses. These analyses were also based on the weighted statistic described above. Under this analysis, children produced significantly more codas in high phonotactic probability nonwords $(M=4 \cdot 56, S . D .=2 \cdot 6 \mathrm{I})$ than in low probability non-words $(M=3 \cdot 86$, $S . D .=2 \cdot 4) ; t=(28)=-\mathrm{I} \cdot 88, p<0 \cdot 05$, one-tailed paired $t$-test. Eight out of I I items were also produced more accurately in the high probability nonwords $(M=\mathrm{II} \cdot 44, S . D .=5 \cdot \mathrm{I} 4)$ than in the low probability non-words $(M=9.5 \mathrm{I}, \quad S . D .=5.98)$; however, this difference was not significant, $t(\mathrm{I} \circ)=-\mathrm{I} \cdot 09, p>0 \cdot 05$, one-tailed paired $t$-test. The lack of a reliable item effect is in part due to the pair /gim//bom/, which patterned in the opposite direction. Children often produced these non-words as [gem] 'game' and [bon] 'bone', respectively. 
TABLE 3. Weighted response by items, for correct codas in Low and High PP non-words

\begin{tabular}{|c|c|c|c|}
\hline \multicolumn{2}{|c|}{ Phonotactic probability } & \multicolumn{2}{|c|}{ Correct } \\
\hline Low & High & Low & High \\
\hline $\mathrm{t} \int \Lambda \mathrm{d}$ & $\mathrm{g} \varepsilon \mathrm{d}$ & $6 \cdot 52$ & I I $\cdot \circ$ \\
\hline $\mathrm{p} \Lambda \mathrm{l}$ & $\mathrm{g} \varepsilon \mathrm{l}$ & 3.00 & I 2.55 \\
\hline $\mathrm{d}_{3} \Lambda \mathrm{s}$ & tes & $8 \cdot 52$ & I I 59 \\
\hline$\theta æ g$ & sig & $7 \cdot 00$ & I 4.00 \\
\hline$z \varepsilon \mathrm{V}$ & div & $3 \cdot 62$ & $3 \cdot 28$ \\
\hline $\int \Lambda \eta$ & bin & $4 \cdot 34$ & $8 \cdot 72$ \\
\hline gim & bom & $7 \cdot 72$ & $2 \cdot 90$ \\
\hline von & $\operatorname{nin}$ & $6 \cdot 00$ & I 4.00 \\
\hline $\mathrm{d}_{3}$ JIs & fais & I $6 \cdot 4 \mathrm{I}$ & I 6.14 \\
\hline loIn & rain & $3 \cdot 45$ & $5 \cdot 24$ \\
\hline mord & naId & $4 \cdot 69$ & $6 \cdot 2 \mathrm{I}$ \\
\hline
\end{tabular}

The above analyses are consistent with the hypothesis that a non-words' phonotactic probabilities influences children's accuracy of coda production. However, other accounts may be possible. The difference in children's coda productions across the low and high pairs might be driven by the onsets' place of articulation, the onsets' manner of articulation, the onsets' age of acquisition, or a combination of onset characteristics, which varies across the members of the pairs. The following analyses examine whether support for these four alternative hypotheses is found in the data.

With respect to the onsets' place of articulation (POA), nine of the I I pairs had at least one member with a different POA in the onset and coda. In the case of consonant harmony (specifically progressive harmony), if the codas in low phonotactic probability non-words are more likely to assimilate to their onsets' POA, this might account for why children were less accurate at producing codas in the low phonotactic probability non-words. The relevant pairs can be seen in Table 4. To evaluate this hypothesis, children's productions were examined to determine whether any incorrectly produced coda could be attributed to the onsets' POA. For example, with the nonword $/ \mathrm{g} \varepsilon \mathrm{d} /$, the onset has dorsal POA and the coda has coronal POA. If a child produced $[\mathrm{k}]$ in coda position, as in the case of $[\mathrm{gck}]$, the child has made an error in the codas' POA. The coda now has the same POA specification as its preceding onset. Real Word responses were not included in this analysis.

There were more errors in children's POA productions in low versus high phonotactic probability non-words that could potentially be attributed to the onsets' POA (I7 vs. 8). A closer look at children's responses showed that in only eight of these responses (when children produced a coda 
TABLE 4. Codas undergoing consonant harmony that could be attributed to the preceding onsets' place of articulation

\begin{tabular}{|c|c|c|c|}
\hline \multicolumn{2}{|c|}{ Phonotactic probability } & \multirow[b]{2}{*}{ Low } & \multirow[b]{2}{*}{ High } \\
\hline Low & High & & \\
\hline $\mathrm{t} \int_{\Lambda} \mathrm{d}$ & $\mathrm{g} \varepsilon \mathrm{d}$ & $\mathrm{n} / \mathrm{a}^{\mathrm{a}}$ & 3 \\
\hline $\mathrm{p}_{\Lambda} \mathrm{l}$ & $\mathrm{g}_{\varepsilon l}$ & 0 & 0 \\
\hline $\mathrm{d}_{3} \Lambda \mathrm{S}$ & tes & $\mathrm{n} / \mathrm{a}$ & $\mathrm{n} / \mathrm{a}$ \\
\hline$\theta æ g$ & sig & 4 & 0 \\
\hline$z \varepsilon v$ & div & 5 & 5 \\
\hline $\int \Lambda \mathrm{Y}$ & bin & 4 & 0 \\
\hline gim & bom & I & $\mathrm{n} / \mathrm{a}$ \\
\hline von & $\operatorname{nin}$ & 3 & $\mathrm{n} / \mathrm{a}$ \\
\hline $\mathrm{d}_{3}$ गIs & fais & $\mathrm{n} / \mathrm{a}$ & 0 \\
\hline loin & rain & $\mathrm{n} / \mathrm{a}$ & $\mathrm{n} / \mathrm{a}$ \\
\hline mord & nard & $\circ$ & $\mathrm{n} / \mathrm{a}$ \\
\hline Total & & I 7 & 8 \\
\hline
\end{tabular}

${ }^{a}$ Onset and coda already share place of articulation.

response with POA harmony), the coda in the corresponding non-word pair was also produced correctly. For a conservative analysis to determine whether these eight cases could change the outcome of the results, a reanalysis was done in which children's response for the pair was treated as a No Response. For example, one subject produced / $\theta æ g /$ as [tæt] and /sıg/ as [tig]. The responses for the pair $/ \theta æ g /$ and $/ \mathrm{sig} /$ were both re-coded as No Response, and the weighted statistic was recalculated. A subjects analysis revealed that children were still significantly more likely to produce codas accurately in high phonotactic probability non-words $(M=3 \cdot 5, S . D .=\mathrm{I} \cdot 99)$ than in low phonotactic probability non-words $(M=2.55, S . D .=\mathrm{I} \cdot 68)$, $t(28)=-3 \cdot 24, p<0 \cdot 0 \mathrm{I}$, one-tailed paired $t$-test. This held across an items analysis, where codas were produced more accurately in the high probability non-words $(M=8 \cdot 78, S . D .=4 \cdot 35)$ than in the low probability version $(M=6 \cdot 24, \quad S . D .=3 \cdot 82), \quad t(\mathrm{I} \circ)=-2 \cdot 2, \quad p<0.05$, one-tailed paired $t$-test. Therefore, the alternative POA analysis does not challenge the hypothesis that coda productions are influenced by phonotactic probability. ${ }^{3}$

With respect to the onsets' manner of articulation (MOA), five of the I I

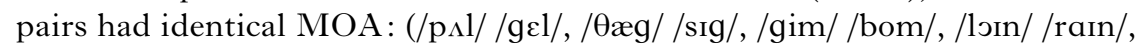
and $/ \mathrm{mord} / / \mathrm{nard} /$ ). Of these five pairs, four showed the predicted effect

[3] Previous research has shown that regressive harmony occurs more often than progressive harmony (e.g. Pater \& Werle, 200I). This was not found across the low and high probability non-words. There were I3 cases of regressive harmony and 25 cases of progressive harmony. A further observation not attested is the preference for coronals to be targeted for assimilation (e.g. Pater \& Werle, 200I). There I I cases of coronal assimilating ( 5 initial, 6 final) and 27 cases of non-coronal assimilating ( 8 initial and I 9 final cases). 
where codas in high phonotactic probability non-words were produced more accurately than codas in low phonotactic probability non-words. Six of the I I pairs differed in the MOA: $\left(/ \mathrm{t} \int \Lambda \mathrm{d} / / \mathrm{g} \varepsilon \mathrm{d} /, / \mathrm{d}_{3} \Lambda \mathrm{s} / / \mathrm{t} \varepsilon \mathrm{s} /, / \mathrm{z} \varepsilon v / / \mathrm{d} \mathrm{sv} /\right.$, $/ \mathrm{f} \Lambda \mathrm{y} / / \mathrm{bin} /$, /von/ /nin/, and /dzכis/ /fais/). For example, in the pair/zev/ /div/, the non-word /zev/ begins with a fricative, whereas /dıv/, begins with a stop. Of these six pairs, four showed the predicted effect of phonotactic probability on coda production. Given that the predicted effects were obtained regardless of whether pairs had differences in MOA, it is unlikely that this variable can account for the phonotactic probability effects observed in children's productions.

With respect to age of acquisition, some onsets across the low phonotactic probability pairs contain late-acquired phonemes. For instance, the onset $/ \mathrm{t} / /$ in the low phonotactic probability non-word $/ \mathrm{t} \int \Lambda \mathrm{d} /$ is acquired later in English than the onset $/ \mathrm{g} /$ of the matched pair $/ \mathrm{g} \varepsilon \mathrm{d} /$ (Smit, Hand, Freilinger, Bernthal \& Bird, I990). Note that children were not evaluated on how they produced the non-words' onsets, i.e. children's production of $/ \mathrm{t} \int \Lambda \mathrm{d} /$ as either $\left[\mathrm{t} \int \Lambda \mathrm{d}\right]$ or $[\mathrm{t} \Lambda \mathrm{d}]$ was coded as a correct production of $/ \mathrm{d} /$. If we assume that late acquired consonants are articulatorily more difficult, it is possible that children's difficulty in producing a late acquired onset 'costs' a degree of articulatory movement, memory or processing load. This in turn might have affected children's ability to produce the codas correctly. To more directly test the hypothesis that accuracy of onset production is negatively related to accuracy of coda production, a Pearson correlation was performed on correct onsets and correct codas for the i I low phonotactic probability non-words. The hypothesis was not supported $(r(9)=0 \cdot 26$, $p>0.05$, one-tailed). In fact, the coda the children produced least accurately was in the non-word $/ \mathrm{p} \Lambda \mathrm{l} /$, which contains an onset that is acquired relatively early.

As a final search for an alternative explanation to the pattern of coda productions observed, we can combine the analyses of MOA and late acquired phonemes. We took a closer look at the low phonotactic probability member in the six pairs that differed from their matched pair on MOA and age of acquisition: $\left(/ \mathrm{t} \int \Lambda \mathrm{d} /, / \mathrm{d}_{3} \Lambda \mathrm{s} /, / \mathrm{z} \varepsilon \mathrm{v} /, / \int_{\Lambda \mathrm{y}} /, / \mathrm{von} /\right.$, and $/ \mathrm{d}_{3}$ IIs/). In three of these non-words, when children produced the onsets accurately, they produced the codas less accurately: $/ \mathrm{t} \int \Lambda \mathrm{d} /, / \int \Lambda \mathrm{y} /$ and $/ \mathrm{d}_{3}$ JIs/. However, the other three cases show the opposite pattern, in which children were more accurate at producing codas when the onsets were also produced correctly: $/ \mathrm{d}_{3} \Lambda \mathrm{s} /$, /von/ and / $\mathrm{d}_{3}$ эIs/. In summary, the best available explanation for the data in the current study is that phonotactic probability had a significant impact on children's production of coda consonants.

The second goal of the current study was to compare the results with those of earlier studies. In particular, we examined children's rhyme productions to determine if they showed similar patterns as those observed 


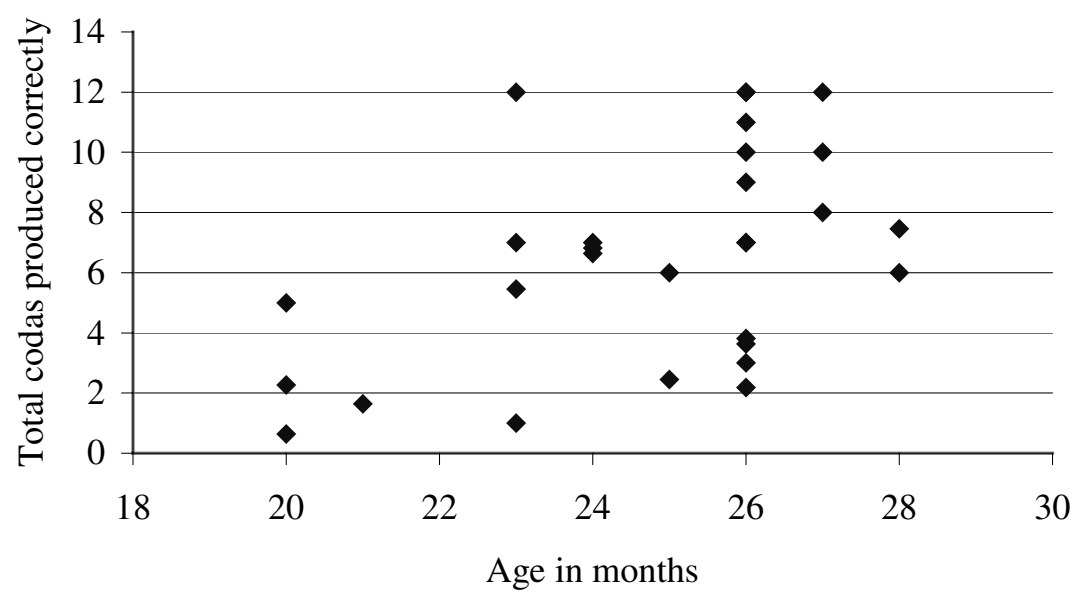

Fig. I. Children's correct production of coda consonants collapsed across low and high phonotactic probability words as compared to subjects' ages in months.

in coda productions. We also sought possible correlations between age, vocabulary and effects of phonotactic probability. We performed several analyses to determine the effects of phonotactic probability on rhymes, effects that were not found in older children by Beckman \& Edwards (2000). Using the weighted statistic described above and with Real Word responses excluded, an analysis by subjects revealed that subjects were more likely to produce rhymes accurately in high phonotactic probability non-words $(M=3.03, S . D .=\mathrm{r} \cdot 87)$ than in low phonotactic probability non-words $(M=$ $\mathrm{I} \cdot 87$, S.D. $=\mathrm{I} \cdot 44$ ). Twenty-one children produced rhymes more accurately in high phonotactic probability non-words, five children produced rhymes equally correct across the pairs, and three children produced more rhymes accurately in the low phonotactic probability non-words. This difference was significant $(t(28)-3.74, p<0.00 \mathrm{I}$, one-tailed). Nine of the I I items were produced more accurately in the high probability $(M=7.67$, $S . D .=3 \cdot 83)$ than in the low probability version $(M=4.52$, S.D. $=\mathrm{I} \cdot 83)$, which was a significant difference ( $t$ ( $о 0)-2.94, p<0.0 \mathrm{I}$, one-tailed). The same pattern of results were observed when Real Word responses were included. Possible reasons for the differences found in the two studies are presented in the discussion.

With respect to the relation of age to coda production, we found a significant correlation between subjects' ages and the total correct codas produced across low and high phonotactic environments, such that older subjects gave more correct responses, $r=0.48, n=27, p<0 \cdot 0$ I, two-tailed. A scatter plot of these results is given in Figure $\mathrm{I}$. 


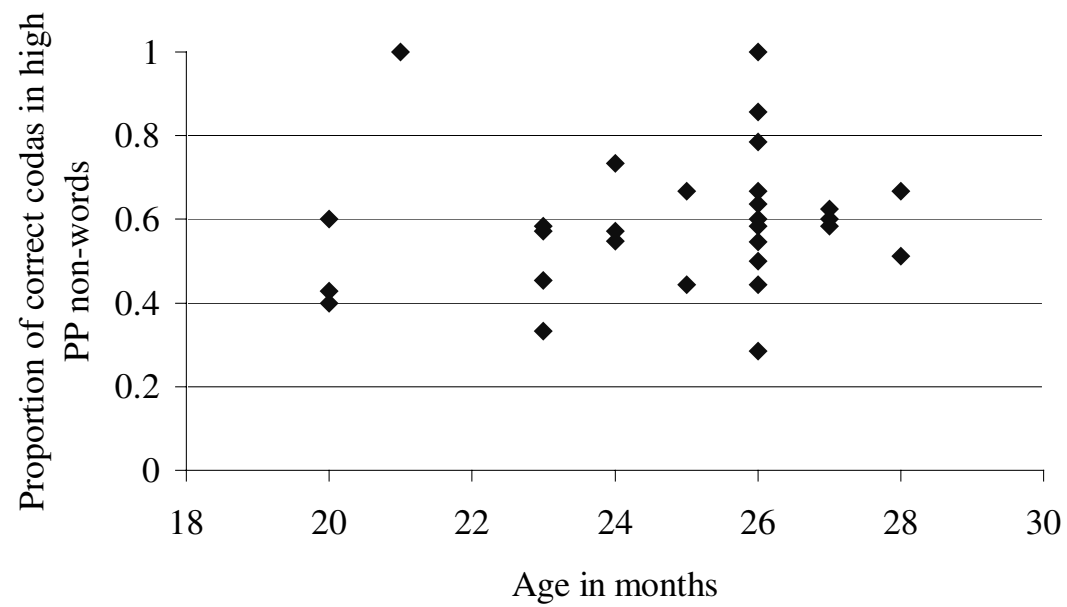

Fig. 2. Proportion of correct codas produced in high phonotactic probability non-words as compared to subjects' ages in months.

Separate correlations were performed on the relation of age to coda production in low and high phonotactic probability environments ( $r$ low probability $=0.34, p<0.10 ; r$ high probability $=0.50, p<0.01)$. To determine whether children performed quantitatively different on their productions of codas in the low and high phonotactic probability pairs, subjects' ages were correlated to the proportion of correct codas produced in high phonotactic probability non-words. The correlation was not significant, $r=0.12, n=27, p>0.05$, two-tailed. A scatter plot of this relation is given in Figure 2.

Lastly, analyses determined whether the effect of phonotactic probability in children's productions is also a function of children's vocabulary size, as measured by the Vocabulary Checklist of the CDI (Fenson et al., I993). Children's ages and vocabulary sizes were first correlated; however, no significant relation was found between the two, $r=0.04, n=27, p>0.05$, two-tailed. There was also no correlation between children's vocabulary size and the number of codas produced correctly $(r=0 \cdot 18, n=27, p>0 \cdot 05$, twotailed) or between children's vocabulary size and the difference between codas produced in low and high phonotactic probability non-words $(r=0.23$, $n=27, p>0.05$, two-tailed). Given that the study by Edwards et al. (2001) looked at effects of phonotactic probabilities on children's production of $\mathrm{CV}, \mathrm{CC}$ and $\mathrm{VC}$ sequences rather than singleton coda productions, further correlation analyses were done on children's rhyme productions to parallel the previous study. However, there was no correlation between children's vocabulary size and the numbers of rhymes produced correctly $(r=0 \cdot 17$, 
$n=27, p>0.05$, two-tailed) or between children's vocabulary size and the difference between rhymes produced in low and high phonotactic probability non-words ( $r=0.14, n=27, p>0.05$, two-tailed). To summarize, although younger children produce fewer codas than older children, children at all of the ages tested appear to produce more codas in high over low phonotactic probability non-words. This appears to be a function of children's age, rather than their vocabulary size, given that no significant relationship was found between children's productions and the size of their lexicons.

\section{DISCUSSION}

There were two central goals of the experiment. The first goal was to determine whether children's coda productions were a function of the non-words' probabilistic phonotactics. Children were significantly more likely to produce the same coda in high phonotactic probability non-words than in low phonotactic-probability non-words. These results are consistent with the hypothesis that phonotactic probability is a predictor of coda production in English. Moreover, this finding provides further evidence for the role of the input and the distribution of sound patterns in the ambient language as a basis for phonological acquisition. The results show that children do not just progress from deleting codas to eventually producing them (Jakobson, I94I/I 968) or even that children do not just produce more frequent codas before infrequent codas (Stoel-Gammon, I 998; Zamuner, 2003). Rather, the results illustrate that children differentially produce the same coda depending on the non-word's phonotactic environment.

The second goal was to compare results from this experiment against previous research. One comparison was to the results on rhyme production from Beckman \& Edwards' (2000) study. The results of this experiment differ from those in Beckman \& Edwards', who found a significant effect of phonotactic probabilities in children's non-word onsets and clusters productions, but not in children's rhyme productions. In the current study, a significant effect of the non-words' phonotactic probabilities was found on children's rhyme production. Several reasons might account for this discrepancy. Beckman \& Edwards write that familiar non-words were often made into real words, e.g. the final syllable in the familiar non-word /bəd'og/ was produced as 'dog'. A higher proportion of real word substitutions with familiar rhymes might account for why no effect was found, especially given that they did find an effect of familiarity on rhyme production with children with phonological disorders. Another reason why differences were found between the two studies has to do with the nature of the stimuli. Beckman \& Edwards' stimuli were identical except for the rhymes, whereas the stimuli in this experiment had varying onsets. To illustrate, take the low and high non-word pair in Beckman \& Edwards' 
stimuli of /bəd'ug/ and /bəd'og/, vs. / $\theta æ g /$ and /sıg/, respectively. Because their stimuli were more controlled, the overall segmental positional probabilities of the non-word stimuli would also be more similar. Therefore, the overall structure of the non-words were not identical across the experiments, and they are not completely comparable. Beckman \& Edwards also did not include late acquired phonemes in their stimuli, such as $/ \theta /$, which was included in this experiment. It is less likely that this factor can account for the differences between experiments. Although a few late acquired phonemes were included in this experiment in onset position, subjects were not penalized for mispronunciations of onsets. Additional analyses also showed that the accuracy of children's onset productions was not negatively correlated to the accuracy of children's coda productions. A third difference was that Beckman \& Edwards' stimuli contained disyllabic and trisyllabic non-words, e.g. /gəd'otup/ and /gəd'otaup/, whereas, the current study only used monosyllables. Therefore, some rhymes in Beckman \& Edwards' experiment were in unstressed position, whereas the stimuli in this experiment were always stressed. It could be then that children are worse at producing unstressed syllables, so much so that any potential effects of unfamiliarity and familiarity were masked. Again, this account seems less likely because they also found that children with phonological disorders showed effects of familiar vs. unfamiliar with these same stimuli. Children with phonological disorders also have difficulty producing unstressed syllables (Goffman \& Smith, I999; Carter \& Gerken, 2003), so one would expect them to have similar difficulties to the children with normal development.

In keeping with the second goal of the experiment, we also looked at possible relationships between age and effects of phonotactic probability on children's coda productions. In this experiment, an attempt was made to include subjects as young as possible $(\mathrm{I} ; 8)$ to determine whether their performance would differ from older children's performance $(2 ; 3-2 ; 4)$. In fact, younger children performed quantitatively, but not qualitatively differently. That is, the same pattern of responses held across the different aged subjects, though the younger participants gave fewer responses overall. Thus, these results are consistent with results found in previous experiments looking at the productions of older children (Treiman et al., 2000; Munson, 200I). Lastly, previous research also noted that children with higher productive and receptive vocabulary scores had smaller influences of frequency than children with smaller vocabularies (Edwards et al., 200 I), yet no significant relationship between the two was found in this study. One of the major differences between the studies is the age range of the subjects. Children in the previous study were between the ages of $3 ; 2-8$; 10 . Children in this study were aged $\mathrm{I} ; 8-2 ; 4$, and at the beginning stages of word production. There was very little variation in subjects' vocabulary scores in the 
current study. Seventeen of the 29 subjects had vocabulary scores within half a standard deviation from the mean. Therefore, it is very likely that the reason why no relationship was found between vocabulary scores and phonotactic probability is because the subjects' vocabulary size in this study were too homogenous.

Another reason for the differences seen across the studies might be in the nature of the stimuli. In the previous study, children were tested on $\mathrm{CV}$, $\mathrm{CC}$ and $\mathrm{VC}$ sequences and within the set of low phonotactic probability non-words, sequences comprised both attested and non-attested forms. Further analyses showed that children with higher vocabulary scores produced both attested and unattested forms more accurately than children with low vocabulary scores. Based on this, Edwards et al. argue that children with higher vocabulary scores have more robust generalizations and representations which are independent of context, given that these children produced unattested sequences equally well as attested sequences. Note that children in this study were compared on their productions of identical codas across high and low probability environments. It could be then that any potential differences in the strength or nature of children's phonological representations based on vocabulary size, might not be sensitive enough to measures of how the same coda is produced. This account seems less likely, however, because rhyme analyses were also done for children's responses in this experiment, and there was no significant relationship between subjects' vocabulary scores and proportion of rhymes produced correctly. An increased number of subjects from a younger age and with a wider range of vocabulary scores are needed to further examine the relationship between children's lexicon size and their production abilities.

An alternative account for the findings of this study is that children's errors were based in perception rather than in production. It was assumed in this study that children were able to correctly perceive the non-words' codas. This assumption was based on the adult pilot experiment in which adults were able to correctly perceive and produce the codas. Further evidence to suggest that children were able to correctly perceive the stimuli comes from a study by Edwards, Fox \& Rogers (2002), who found that children as young as 3;0-4;0 performed above chance in discriminating between the minimal pairs 'cap' and 'cat' or 'tap' and 'tack'. Other studies from infant speech perception have shown that infants as young as seven and a half months are able to discriminate minimal pairs which differ only on the place of articulation of the final segment (Tincoff \& Jusczyk, r 996). Because infants and children are able to perform the task, this suggests that children's perception of final consonants is quite good. It is still possible that some errors are based in perception. In this case, codas in low phonotactic probability environments would be less perceivable that codas in high phonotactic probability environments. This is consistent with the theory 
that children's experience with language influences their ability to perceive and produce language. Further studies are needed to explore the role of perception in the production task described in this study and in similar studies.

The results obtained in this experiment are consistent with previous research showing that infants, children and adults are sensitive to patterns of probabilistic phonotactics, and that subjects show a preference for nonwords composed of high phonotactic probabilities. This research has used a variety of tasks such as the Headturn Preference Procedure, judgements of the relative well-formedness of non-words, reaction times, and memory tasks; the results from this study extend this research into the productions of young children between the ages of $1 ; 8-2 ; 4$. Results of the experiment presented here suggest that children's productive language reflects children's experience with language more than previously believed in phonological acquisition research. There are a number of ways in which the results can be accounted for, which relate to children's processing, representations, and to children's perception and production of language.

One explanation of children's more accurate production of codas from high probability phonotactic environments is that their performance reflects acquired production templates, such that non-words which are similar to acquired templates would have an advantage in the accuracy of production (e.g. Gerken, I994; Vihman \& Velleman, 2000; Fikkert \& Levelt, 200 I). A similar explanation is that children's accuracy on the non-word repetition task may reflect their sublexical representations, as suggested by Beckman \& Edwards (2000). Under this account, if children's lexical representations are stored as sub-units, they are then able to access more stable units with increased accuracy. At the time of production, these non-words' representations may have an advantage in that they can be accessed faster and more accurately than other non-words that might not have as detailed representations. This suggests that children at this stage of language acquisition might not yet have distinct phonemic representations of codas. That is, young children might not have a context free representation of $/ \mathrm{d} /$, but rather, they may have multiple representations of $/ \mathrm{d} /$, which are distinguished by different syllabic positions within words, and/or distinguished with respect to the /d/'s phonotactic environment. The notion that children's early phonological representations are richly detailed would further illustrate the continuity across development from infant speech perception to child language production. Here, the representations that are built up during infancy are reflected and have a role in children's developing system. Results from Fisher, Hunt, Chambers \& Church (200I) further support this hypothesis. This study found effects of auditory priming in children's productions between the ages of $2 ; 4-2 ; 7$. Experience with sound patterns improves children's repetition of non-words, suggesting that children's 
representations of sounds encode token specific details, and that knowledge accumulates over time.

The results obtained in this study illustrate the importance of considering the input in young children's acquisition of phonology. Although the study looks at children's production of non-words, the results have broader implications because phonological knowledge relates to the development of lexical representations. Recent research looking at the composition of two children's developing lexicons between the ages of $2 ; 6-3 ; 6$ has found that children learn the most frequent sounds and sound combinations first (Coady \& Aslin, 2003). It is important to know then, whether children's production accuracy reflects the frequency of the sounds attempted. Moreover, it is also important to look at the development of children's phonology across specific lexical items, which is the focus of recent studies on lexical diffusion examining word frequency and neighbourhood densities with respect to sound changes in children's systems (e.g. Morrisette, I 999; Gierut \& Storkel, 2002; Storkel \& Gierut, 2002). Focusing just on word frequency, studies like that of Storkel \& Gierut have looked at longitudinal data on fricative development from children with functional phonological disorders. They found that sound changes occurred more often on low frequency words than high frequency words. This does not tell us, however, whether children's initial productions are more or less accurate on low or high frequency words. However, it does illustrate that word frequency (and neighbourhood densities) need to be considered when looking at how children's phonological systems develop. Regardless of the direction of the effect, research in child phonology often collapses across word types, such as looking at children's acquisition of /d/ based on children's productions of the words 'bad' and 'shed'. Yet, the frequency of the words 'bad' and 'shed' and the word's segmental and positional probabilities differ. Consequently, a distorted picture of children's development would be obtained based on these words, given that children differentially produce the same consonants depending on the probability of sound patterns in the whole word. In addition to controls for word frequency, analyses are also needed of children's phonological systems, given that these systems can influence children's perception and production of language. One could then determine whether children's phonological systems interact with their performance on tasks like the one described in this paper. There is insufficient data from the subjects tested in this study to make analyses or claims about their phonological systems. This is a limitation of the current study. Although the findings here require future studies to be more controlled, they will also allow for a greater understanding of how children acquire language. Specifically, the hope is that detailed analyses of sound patterns in the ambient language will help account for variability seen in acquisition, which has long been argued to require explanation. With finer grained analyses, 
what was previously unaccounted for and labelled as variation might now be seen to reflect the input and the nature of children's phonological representations.

\section{REFERENCES}

Beckman, M. E. \& Edwards, J. (2000). Lexical frequency effects on young children's imitative productions. In M. Broe \& J. Pierrehumbert (eds), Papers in laboratory phonology $V$ : Language acquisition and the lexicon. Cambridge: CUP.

Bernstein-Ratner ( 1994). Phonological analysis of child speech. In J. L. Sokolov \& C. E. Snow (eds), Handbook of research in language development using CHILDES. Hillsdale, NJ : Erlbaum.

Brown, R. (1973). A first language: the early stages. Cambridge, MA: Harvard University Press.

Carter, A. K. \& Gerken, L. A. (2003). Similarities in weak syllable omissions between children with specific language impairment and normally developing language: a preliminary report. Fournal of Communication Disorders 36, I65-79.

Coady, J. A. \& Aslin, R. N. (2003). Phonological neighbours in the developing lexicon. Fournal of Child language 3o, 44I-69.

Davis, S. (I 989). Cross-vowel phonotactic constraints. Computational Linguistics I4, Iо9-ıо.

Demuth, K. \& Fee, E. J. (I995). Minimal prosodic words in early phonological development. Unpublished manuscript, Brown University, Providence, RI and Dalhousie University, Halifax, Canada.

Edwards, J., Beckman, M. E. \& Munson, B. (2001). The interaction between vocabulary size and phonotactic probability effects on children's production accuracy and fluency in novel word repetition. Manuscript submitted for publication.

Edwards, J., Fox, R. A. \& Rogers, C. L. (2002). Final consonant discrimination in children: effects of phonotactic disorder, vocabulary size, and articulatory accuracy. Fournal of Speech, Language, and Hearing Research 45, $23 \mathrm{I}-42$.

Fenson, L., Dale, P. S., Reznick, J. S., Thal, D., Bates, E., Hartung, J. P., Pethick, S. \& Reilly, J.S. (1993). The MacArthur Communicative development inventories: user's guide and technical manual. San Diego, CA: Singular Publishing Group, Inc.

Fikkert, P. (1994). On the acquisition of prosodic structure. Leiden: Holland Institute of Generative Linguistics.

Fikkert, P. \& Levelt, C. (200I). Putting place in place. Paper presented at the GLOW Phonology Workshop and Fifth Utrecht Biannual Phonology Workshop, Utrecht, The Netherlands.

Fisher, C., Hunt, C. M., Chambers, K. \& Church, B. A. (200I). Abstraction and specificity in preschoolers' representations of novel spoken words. Fournal of Memory $\mathcal{F}^{\circ}$ Language 45, 665-87.

Gerken, L. A. (I994). A metrical template account of children's weak syllable omissions. Fournal of Child Language 21, 565-84.

Gierut, J. A. \& Storkel, H. L. (2002). Markedness and the grammar in lexical diffusion of fricatives. Clinical Linguistics \& Phonetics I6, I I 5-34.

Goffman, L. \& Smith, A. (I999). Development and phonetic differentiation of speech movement patterns. Fournal of Experimental Psychology: Human Perception and Performance $\mathbf{2 5}, 649-60$.

Hammond, M. (200I). English phonotactics and probabilistic phonology. Paper presented at Southwestern Workshop on Optimality Theory (SWOT) 6, University of Southern California.

Jakobson, R. (1968). Child language, aphasia, and phonological universals. The Hague: Mouton. (Original work published in I94I).

Jusczyk, P. Q., Luce, P. A. \& Charles-Luce, J. (I994). Infant's sensitivity to phonotactic patterns in the native language. Fournal of Memory and Language 33, 630-45. 
Messer, S. (1967). Implicit phonology in children. Fournal of Verbal Learning and Verbal Behavior 6, 609-13.

Morrisette, M. L. (I999). Lexical characteristics of sound change. Clinical Linguistics and Phonetics 13, 21 $19-38$.

Moskowitz, A. I. (I970). The two-year-old stage in the acquisition of English phonology. Language 46, 426-4I.

Munson, B. (200I). Phonological pattern frequency and speech production in adults and children. Fournal of Speech, Language and Hearing Research 44, 778-92.

Pater, J. \& Werle, A. (200I). Typology and variation in child consonant harmony. In C. Féry, A. Dubach Green \& R. van de Vijver (eds), Linguistics in Potsdam, vol. I2: Proceedings of the 5th Holland Institute of Linguistics Phonology Conference. University of Potsdam.

Pierrehumbert, J. (1994). Syllable structure and word structure: a study of triconsonantal clusters in English. In P. A. Keating (ed.), Phonological structure and phonetic form: papers in laboratory phonology III. Cambridge: CUP.

Smit, A. B., Hand, L., Freilinger, J. J., Bernthal, J. E. \& Bird, A. (I990). The Iowa articulation norms project and its Nebraska replication. Fournal of Speech and Hearing Disorders 55, 779-98.

Stoel-Gammon, C. (1998). Sounds and words in early language acquisition: the relationship between lexical and phonological development. In R. Paul (ed.), Exploring the speechlanguage connection. Baltimore: Paul $\mathrm{H}$. Brookes Publishing Co.

Storkel, H. L. (200I). Learning new words: phonotactic probability in language development. Fournal of Speech, Language, and Hearing Research 44, I 32 I-37.

Storkel, H. L. \& Gierut, J. A. (2002). Lexical influences on interword variation. In B. Skrabela, S. Fish \& A. H. J. Do (eds), Proceedings of the 26th Annual Boston University Conference on Language Development. Somerville, MA: Cascadilla Press.

Tincoff, R. \& Jusczyk, P. (I996). Are word-final sounds perceptually salient for infants? Poster presented at the Fifth Conference on Laboratory Phonology, Evanston, Illinois.

Treiman, R., Kessler, B., Knewasser, S., Tincoff, R. \& Bowman, M. (2000). English speakers' sensitivity to phonotactic patterns. In J. Pierrehumbert \& M. Broe (eds), Papers in laboratory phonology $V$ : language acquisition and the lexicon. Cambridge: CUP.

Vihman, M. M. \& Velleman, S. L. (2000). The construction of a first phonology. Phonetica $\mathbf{5 7}, 255^{-66 .}$

Vitevitch, M. S. \& Luce, P. A. (I 998). When words compete: levels of processing in spoken word recognition. Psychological Science 9, 325-29.

Vitevitch, M. S. \& Luce, P. A. (I999). Probabilistic phonotactics and neighbourhood activation in spoken word recognition. Fournal of Memory and Language 4o, 374-408.

Webster, M. (1 964). The new Merriam-Webster pocket dictionary. New York: Simon and Schuster.

Zamuner, T. S. (2003). Input-based phonological acquisition. New York: Routledge. 